\title{
Parenting Styles and Aggression Among Young Adolescents: \\ A Systematic Review of the Literature
}

\begin{abstract}
There is ample research on aggression amongst children and adolescents that highlights several antecedents of aggression. While researchers have remarked on the relationship between parenting styles and aggression in children, there are few studies that integrate and systemize the available studies on parenting styles and aggression. The present review is an attempt to fill this gap. For this review, relevant studies were first searched, then coded and classified. As a result of thorough review, 34 relevant studies were identified. The review shows that parenting styles have a direct impact on aggression in children. Authoritative parenting styles playa positive role in psychological behavior in children while authoritarian and permissive parenting styles result in aggressive and negative behaviors in children. The current study also suggests that there is room to conduct studies on this topic in developing countries. Future research should be undertaken in developing and under-developed countries and should focus on mixed modes of research and examine the direct influence of parenting styles on aggressive behavior in children in different cultural contexts.
\end{abstract}

Keywords: Aggression; Child Mental Health; Aggressive Behavior; Family Support; Systematic Literature Review 


\section{Introduction}

During the last few decades, researchers in the field of aggression have devoted their attention to relational, social, and indirect aggression (Underwood, Beron\& Rosen, 2009). For these types of aggression, the term relational aggression is used here to distinguish it from physical aggression. It is conceptually recognized as the type of aggression which usually damages relationships with others. Freud (1937) stated that aggression is a reaction to a varying level of conflicts of interest. It is observed that aggressive children face psychological disturbance. It is a serious mental health issue which is faced by both Western and Eastern countries (McNamara, Selig, \& Hawley, 2010), and in many cases, once it is identified in childhood, it is harmful for the child's psychological growth (Huesmann, Dubow, \& Boxer, 2009). Such children have additional behavioral problems that increase in intensity with the passage of time (Dodge, Coie \& Lynam, 2006). During adulthood, these problems then lead towards behavioral disorders, sometimes resulting in criminal behavior (Huesmann et al., 2009).

The literature on aggression has identified various antecedents. Among them, biological and psychological factors are of greater interest for researchers, who have found family factors as of paramount importance as they directly and indirectly impact on aggressive behavior (Raine, 2002). Parenting style is one of the most dominant factors which directly and indirectly influence psychological growth of children (Crick, Werner, Casas, O'Brien, Nelson, Grotpeter \& Markon, 1999). Studies examining parenting styles and aggression have shown that the way parents interact with their children can have both positive and negative results (Reed, Goldstein, Morris, \& Keyes, 2008). Research on child learning and behavior has shown that differences in behaviors in children occur due to different parenting styles (Collins \&Laursen 1999). The role of parenting in child aggression has even greater impact as child behavior is shaped by the parenting behavior. This fact has been supported by social learning theory (Bandura 1973). According to this theory, people learn from others by observing their actions. In the first stage, people observe the actions which they mentally rehearse later, keeping in mind the ultimate consequences of adopting such behaviors. Later on, they adopt such actions, implementing them in their daily lives. It is equally possible that there may be no change in behavior even after observing actions of other people. Behavioral adjustment and social competence of children is based on understanding their needs and parents limit-setting behavior (Baumrind 1991a). This phenomenon can be better explained with the help of Baumrind's parenting style theory (1971). 
According to the parenting styles theory, there are three different types of parenting behavior which have direct influence on the psychological growth of children which include authoritative, authoritarian and permissive parenting styles. Each of these parenting styles is directly and indirectly associated with psychological growth of children and thus on aggressive behavior but an authoritarian parenting style is particularly linked with aggression and aggressive behavior in children and adolescents. Since aggression can be harmful for both perpetrator and victim, the current review will integrate the studies that analyze the relationship between parenting styles and aggression. Therefore, the goal of the current review is to synthesize and integrate the studies on parenting styles and aggression in order to identify the main methodological factors associated with this relationship.

Research shows that parenting style is the combination of the different sets of parenting behaviors that contribute to competency, child development, or psychopathology (McKee, Colletti, Rakow, Jones \& Forehand, 2008). Child modeling behavior and emotional control are affected by these parenting styles. Also, parenting styles affect the behavioral development of children (Lorber, Egeland \& problems, 2011).Positive and negative behavior in children is the result of these parenting styles. Each parenting style shapes the behavioral adjustment of children (Romano, Tremblay, Boulerice\& Swisher, 2005).Keeping in view the importance of parenting styles in the psychological growth of the child, the current review is an attempt to synthesize and integrate past studies in order to examine the relationship between parenting styles and aggressive behavior of children. For this purpose, 34 relevant studies have been analyzed to examine the relationship. Detailed descriptions of these studies are given in the upcoming sections. The review proceeds with the brief introduction of parenting styles and their relationships to aggression in children. In section 2, a brief overview of the methodology is given. Finally, the review ends with discussion and practical implications.

\subsection{A brief analysis of parenting styles}

Three parenting styles, authoritative, authoritarian, and permissive were derived from the classification of Baumrind's theory (1971).According to Baumrind(1971),

1. Authoritative parents are supportive in nature. They lay down guiding principles and try to maintain a balance in affection and discipline. 
2. Authoritarian parenting represents traditional harsh parenting in which children is required to obey the instructions of their parents. There is also the concept of punishment associated with authoritarian parenting.

3. Permissive parents leave their children free to have their own preferences. Such parents do not restrict the social life of children and encourage them to plan at their convenience.

Parenting styles result in behavioral and psychological adjustments of children. These behavioral and psychological characteristics include: academic achievement (Lamborn et al. 1991), selfreliance, social competence (Steinberg 1990), academic achievement (Steinberg, Elmen\& Mounts, 1989), substance use (Baumrind 1991a), peer group selection (Brown, Mounts et al., 1993) and adolescent drinking and delinquency (Barnes \& Farrell, 1992).

\section{Insert Table 3 here}

The parenting styles of mothers are associated with behavioral strategies at school and children's cognitive control (Tina et al.,1998). In addition, it was found that children showed more determination in classroom and were less vulnerable where mother authoritarian behavior was observed. Parents who raise their children with care and give them proper time as well as facilitate them have a stronger effect on the development of children (Baumrind, 1971). Thus it can be concluded that parenting styles, especially the authoritarian parenting style, have a direct impact on the aggression of adolescents.

\subsection{Objectives of the study}

Following are the objectives of this paper:

- To identify studies related to parenting styles and aggression

- To classify and code studies/articles

- To summarize the contribution of each article

- To highlight the strengths and weaknesses of available literature

- To provide a research agenda on parenting styles and aggression for the future 


\subsection{Research Question}

How effective are parenting styles in reducing aggression among adolescents?

What is the impact of parenting styles on aggression of children?

Which parenting style contributes more towards aggression among adolescents?

Behavioral disorder problems are more prominent in children whose parents practice harsh rules as compared to those whose parents are supportive of their children (Kim et al., 2003). It is observed that behavioral problems in children are the result of the absence of supportive parenting which impacts strong communication with and commitment to children. Supportive parenting has several dimensions which include responsive, supportive, warm, sensitive parenting, and parental monitoring and parental involvement (Beyers, Bates, Pettit, \& Dodge, 2003). The absence or presence of such parenting behavior affects the behavioral development of children (Nelson, Hart, Yang, Olson, \& Jin, 2006). Studies show that authoritative/supportive parenting leads children towards pro-social behavior, more socially competent, less negative and low aggressive behavior(Collins \& Steinberg, 2006).In contrast, authoritarian parenting involves coercive rules, strong discipline, aggressive parenting and low levels of a supportive environment for children and can result in negative behavior and aggression (McNamara, Selig\& Hawley, 2010). Aggression is directly linked with the authoritarian, coercive, and uninvolved parenting styles (Nelson et al., 2006)which cause behavioral disorders and aggression in children (Barry, Frick, \& Grafeman, 2008), and its frequency is less in the permissive parenting styles (Underwood, Beron\& Rosen, 2009).

Hence, the importance of parenting styles is presented to highlight their impact on aggression in children. A detailed overview regarding parenting styles and aggression has been presented in the introduction of this study. The next section discusses briefly the methodology of the current review.

\section{Research Methodology}


For this study, a systematic literature review was carried out to search for and select relevant studies. Such a review helps in integrating and systematically arranging the studies and their results. Also, it helps to provide a thorough analysis of the studies and to identify the challenges that are needed to develop future research. According to Junior et al.(2010), the following steps are require in order to conduct a literature review:

Step 1 - Reputable databases are searched to collect studies relevant to the subject.

Step 2 - The classification system is coded.

Step 3 - The classification system is applied.

Step 4 - On the basis of the coding system, results should be provided.

Step 5-Gaps will be identified by analyzing the themes extracted from codes.

\section{Inclusion and exclusion criteria}

It was determined that only relevant studies should be the part of this review. The criteria for inclusion include studies published in English presenting original data and focusing on parenting styles and aggression. Studies that used measures other than parenting styles for aggression were not included in the review. In addition, meta-analytical studies which were not published are not considered part of this review. Two researchers scrutinized the articles at each stage. As a result of thorough review, 34 relevant studies were selected for this review.

\section{Step 1- Search of relevant database}

In the first step of this study, online databases were searched. All the studies relating to parenting styles and aggression were collected. The search was carried out using keywords, titles of articles and abstracts. Keywords used in the search included "parenting styles", "aggression", "aggressive behavior" and "parenting styles and aggressive behavior of adolescents". Other keywords, like "parenting behaviors and aggression" and "parenting styles and aggression in children" were also used to search for the relevant studies with the help of ISI Web of Knowledge, JStore, and Science Direct.

\section{Step 2- Databases Search}


In the next step, a search for studies published in online journals like Elsevier, Taylor \& Francis, Emerald, Springer, and Sage was carried out. Studies that were not relevant to the parenting styles and aggressive behavior of children were excluded from the study. After the precise selection of studies, 34 articles were included in the review. Next, classification and coding of these selected studies were performed.

\section{Insert Table 1 here}

\subsection{Coding and classification}

The classification framework was designed after screening the studies relevant to parenting styles and aggression. Six major themes were classified and identified. Each classification was coded alphabetically. Classification of framework and coding is shown in Table 1.

\section{Insert Table 2 here}

Classification 1: Studies in the national context. Coding was done from A-C.

Classification 2: Identified parenting styles in relation to aggression. The main purpose was to show the dominance of parenting styles in the study. Studies were coded from A-C.

Classification 3: Studies focus on research method. Studies codification was symbolized from A-D.

Classification 4: Different sector, in which studies were done and were coded from A-C.

Classification 5: Position for parenting style in models. It was coded from A-C.

Classification 6: It was associated with exploring the moderator or mediator variable that was used in the study. It was coded from A-C.

\subsubsection{Results}

Codification of the studies was done that were included in this review. (Table 3)

\section{Insert Table 3 here}

\subsection{National Context}


In this study, the following categories were used to highlight the context in which the study was done: $\mathrm{A}$ is coded for developed countries, $\mathrm{B}$ relates to developing countries, and $\mathrm{C}$ represents under-developed countries.

The analysis showed that most of the studies were directed in developed countries (category A). There was only one study that was conceptual (Fig. 1).

\section{Insert Fig. 1 here}

\subsection{Focus on parenting styles}

In the second classification, parenting styles were the focal point. Studies on "parenting styles and aggression" were classified as A;"parenting styles and other variables that affect aggression" were classified as B; and studies in which "parenting styles was not a dominant factor" were classified as C (Fig. 2).

\section{Insert Fig. 2 here}

The present analysis shows that most of the studies were related to parenting styles and other variables that affect aggression, that is, "category B". There were very few studies that focused solely on parenting styles and aggression and few studies in which parenting style was not a dominant factor.

\subsection{Research methods}

Articles were classified based on research methods as follows (Fig. 3):

A - Qualitative, that is, usually associated with the survey

B - Quantitative, that is, usually associated with a case study

D - Qualitative/Quantitative or Quantitative/Qualitative

E - Cases

Insert Fig. 3 here 
Analysis showed that most of the studies relevant to parenting styles and other variables that affect aggression used quantitative research methods. There were very few studies that used qualitative research methods. Also, there were no studies that used mixed methods of research such as qualitative/quantitative research methods.

\subsection{Economic sector analyzed}

Classification 4 focused on determining which of the studies were done in A- the manufacturing industries, $\mathrm{B}$ - the education sector, or C- other sectors (Fig. 4).

\section{Insert Fig. 4 here}

Results show that the focus of the studies was in the education sector. There were very few studies that focused on organizations.

\subsection{The role of parenting style in current research}

The role of parenting style was analyzed in the review to determine whether it was used as A an independent variable, $\mathrm{B}$ - a dependent variable, or $\mathrm{C}$ - mediator/moderator. (Fig. 5)

\section{Insert Fig. 5 here}

Results reveal that in all of the studies, parenting style was used as an independent variable. None of the studies used it as dependent variable. Also, only in one study, it was used as mediator/moderator variable.

\subsection{Use of mediator, moderator variables in the study}

Mediator and moderator variables were analyzed in the studies that were included in the present review. These were characterized as $\mathrm{A}$ - mediator, $\mathrm{B}$ - moderator, $\mathrm{C}$ - no mediator/moderator variable used. (Fig. 6)

\section{Insert Fig. 6 here}

The review shows that most of the studies did not used mediator or moderator variables. The ratio of mediator to moderator used in the studies was almost equal (i.e., six mediators and seven moderators were used in different studies). It might be possible that parenting styles have direct 
influence on aggression in children. But future studies might investigate this aspect of parenting styles and aggression in children.

\section{Insert Table 4 here}

\section{Results and Discussion}

This study is carried out with the help of past literature which examined parenting styles and aggression in children. Each parenting style has some psychological characteristics to control the behavior of children. Review of current studies shows that both authoritative and authoritarian parenting styles provide psychological control, but their magnitude is different. Authoritative parents show flexibility in their attitude and therefore have low magnitude of psychological control, which in turn is helpful in minimizing aggressive and negative behavior in children, while authoritarian parents exert more psychological control to influence their will on children. That is why the authoritarian parenting style has more negative impacts on child aggressive behavior as compared to authoritative and permissive parenting.

In Fig. 7, some issues are highlighted that need to be explored and investigated in future studies. Category $\mathrm{C}$ was the least addressed category in classification 1. There is only one conceptual paper which is part of this review. Only five of the included studies which analyzed the impact of parenting styles and other variables on aggression were conducted in developing countries (e.g., Batool, 2013; Delores and Todd, 2012; Azmi et al., 2012). This raised a concern that the ratio of conceptual studies is less.

In classification 2, most of the studies focused on parenting styles and other variables to assess their impact on aggression. There were fewstudies that directly assessed the impact of parenting styles on aggression in children and adolescents. Also, there were few studies in which parenting styles were not a dominant factor in analyzing aggression. Past studies show that parenting styles affect aggression in children and affect their behavior. The current review found that the same trend is followed across different geographical boundaries. For example, Delores and Todd (2012) and Shoumei, Ling, and Yingjuan (2014)found that parenting styles and aggression are

directly associated with each other. More specifically, authoritarian parenting results in negative psychological behavior of children while authoritative parenting results in positive child 
behaviors. Butthe literature still lacks enough studies to analyze the direct relationship betweenthe two factors (Trenas, 2012).

Classification 3 consists of studies that used research methods. The current review shows that there were few studies that used qualitative research methods (Category A). Also, there were no survey and case studies. Most of the studies applied quantitative methodology in their studies (for example, Chan, 2010; Gustavo et al., 2010, etc.), while there were no studies that used the mixed method of research (Category D).

The education sector (Category B) was the most frequently analyzed sector in classification 4. Only one study, by Smith et al. (1999), focused on respondents who do not belong to academia; rather they were convicted of assaulted crimes. The rest of the studies focused on respondents from academia. It is therefore suggested that more studies should be conducted in other sectors so that results could be generalized. The review shows that there was no study that used parenting style as a dependent variable (Classification-5). Significant studies used parenting style as the independent variable. Also, there was only one study that used parenting style as a mediator/moderator variable.

Classification 6 highlights the use of different variables used as mediator/moderator. The review shows that there are six studies that used the mediator and seven studies that used moderator variables to measure their impact on aggression.

\section{Insert Fig. 7 here}

The review of selected studies shows that there is a negative and direct association between parenting style and aggression (Hesari\& Hejazi, 2011). For example, the authoritarian parenting style in particular is related to child aggression (Rodriguez, 2010). There is a positive relationship between authoritarian parenting style and verbal aggression (Marion et al.,2009). Permissive and authoritarian parenting styles are considered dysfunctional whereas an authoritative parenting style is an ideal and is the most suitable parenting style for optimal child development (Baumrind, 1966 and 1996). For example, in Wisconsin and northern California, nine high schools (grades 9-12)were analyzed using a large sample of 14- to 18-old students (Steinberg, Lamborn, Darling, Mounts \& Dornbusch, 1994). In these studies, behavioral adjustment and social competence of children was found to be positive in those children who 
rated their parents as authoritative and indulgent as compared to those who rated their parents as neglectful. The other two parenting styles, permissive (indulgent) and authoritarian, showed mixed results (Steinberg et al. 1994).Eider, Aitziber, Francisco, Ana, Jaione and José (2014) found that physical aggression was higher in children of authoritarian mothers having higher testosterone levels. It was also found that testosterone moderated the relationship of aggression in girls and fathers' authoritarian parenting. Smith and Moore (2009) found that gender plays an important role in explaining parenting styles and aggressive behavior in children. In their study, they found that boys are found to be more aggressive when it comes to the authoritarian parenting styles, while girls show a lower degree of conduct problems. Further, they stated that authoritative parenting helps in overcoming negative behaviors. They concluded that children who show disagreement with instructions from parents were more likely to exhibit psychological problems as compared with others who follow the instructions of their parents. In addition, Greening et al. (2009) found that authoritarian parenting styles help in reducing negative and suicidal behavior of children. Furthermore, they found that children who were more depressed showed more suicidal behavior as compared to less depressed children.

Research shows that aggression can be controlled through some indirect ways. For example, Fung, Gerstein, Chan, and Hurley (2013) analyzed the association between aggression and parenting styles and found that psychological distress of parents could be decreased by mental health prevention and intervention programs. These programs, which address the forms of aggressive behavior of children, also help in improving the parenting skills in parents. In another study, Shoumei, Ling, and Yingjuan (2014) found in their study that aggression in children was linked with the education of the father and harsh parenting (authoritarian parenting style). Well educated parents better understand the psychological growth of children, which indirectly helps in overcoming the issue of aggression in children. In another study, Chan (2010) examined the relation between authoritarian parenting styles and aggressive behavior in children and found that authoritarian parenting styles and aggressive behavior are significantly associated with each other. Furthermore, it was suggested that there is a need to offer some training programs to parents to cope with emotions of children. Therefore, it is suggested that parents should participate in different training programs which help them in learning different strategies to develop a healthy family environment. 
In addition, adolescents reported better socio-emotional functioning when they perceived their parents as less authoritarian. Association between physical and indirect aggression and authoritarian and permissive parenting is moderated by testosterone (Eideret al., 2014). Mothers' authoritarian parenting and physical aggression is strengthened due to high testosterone levels in boys. In girls, testosterone moderates the association between physical aggression and fathers' authoritarian parenting. Children's negative coping strategies help in mediating the damaging effects of authoritarian parenting (Chan, 2010). The results suggest that the negative and damaging effects of authoritarian parenting styles may be felt across cultures and societies. The children adapt more negative coping strategies when their mothers show more authoritarian attitude and behavior.

The current review reveals that aggression symptoms become stable with the passage of time (Murray-Close \& Ostrov, 2009). The reason may be that younger children are not able to distinguish aggression while, with the development of cognitive skills in children, children are better able to understand how aggression can used to achieve their goals or to protect themselves. So, in adults, aggression functions become more distinct as compared to children (Murray-Close \& Ostrov, 2009). It is therefore suggested to explore the relationship between age and aggression in future studies.

Parenting behaviors have a strong influence on child development and continue this influence from childhood till later stages of development (Mowder, 2005). The current review studied three parenting styles. As Western parents are authoritative in nature (Liu \& Guo, 2010), so they have a positive influence on the development of children, while harsh parenting is positively related to aggression in children. This relationship can be explained with the help of social learning theory. According to this theory, in the early stages, harsh parenting may be helpful in achieving the desired positive outcomes from children, but it may lead towards proactive aggression (Bandura, 1973). Such an environment may direct children to adopt such parental practices in order to resolve their social problems (Chan, 2011) so they start adopting and practicing such strategies in daily social life to avoid problems. The review also highlights that there is no association between authoritative parenting style and aggression. The reason is that authoritative parents involve themselves with their children and help them in overcoming their issues. Such parents are also termed as indulgent parents who are highly involved in their 
children's social life and tolerate their mistakes (Chen et al., 2000) which in turn help in overcoming the aggressiveness in children.

\section{Conclusion}

This study aims to assess the impact of parenting styles on aggression in children and adolescents. Such a review is helpful and useful for the scientific community. Studies relevant to parenting styles and aggression were first selected and then classified. With the help of six recommendations, a research agenda is presented. A research gap is also presented which may strengthen and guide researchers to conduct future research on the relationship between parenting styles and aggression.

The current review shows that authoritative parenting results in positive behavior in children while authoritarian parenting results in aggressive and negative behavior in children. Furthermore, parents 'income also plays an indirect role in aggression in children (Batool, 2013). Adding to this, parenting education also plays an important role in aggressive behavior in children. Higher education among parents results in decreased aggressive behavior in children. However, there is need of further studies to elaborate the relationship comprehensively. Educated parents are better able to develop the personality of children resulting in a smaller chance that their children will have negative behaviors (Shoumei et al., 2014). The review suggests that there is a strong need to understand the parenting style and training of parents in order to aid them in adopting a particular parenting style that will help them overcome the problem of aggression in children and adolescents. In addition, there is a need to conduct studies in developing countries to compare the effect of parenting styles from different cultures and communities. This will help the trainers, educational institutions, parents and, ultimately, children and adolescents.

Lamborn et al., (1991) contradicted the Baumrind theory of parenting styles by stating that authoritative parents were already aware of the psychological needs of their children, so this does not relate to the controlling factor of parents. Lewis (1981) also concluded that children with positive outcomes are not directly associated with firm enforcement of an authoritative parenting style, while kids whose parents were not controlling (permissive parents) also performed well. In traditional structures, there is no need for a controlling factor, so Baumrind's perception of a controlling factor is not applicable.

Though this study shows important findings, there are still some limitations. This study is review analysis. Meta-analytic reviews will produce a deeper understanding of the relationship of 
parenting styles and aggression. The studies included in this review focused on the parenting aspect of parenting styles. Responses from children would be useful in order to avoid the problem of common method bias.

\section{Future research}

This study examined past studies to analyze the relationship between parenting styles and aggression. Based on the current review, some recommendations are suggested to future scholars to draw more insights into the relation between parenting styles and aggression in children. First, more studies are needed in developing and under-developed countries to generalize the impact of parenting styles and other variables on aggression and to compare the national context and understand characteristics of parenting styles in different economic settings. Second, more studies are needed to examine the direct relationship between parenting styles on the aggression of children and adolescents. The current review shows that fewer studies focused on direct association between the variables. Most of the studies focused on an indirect relationship between parenting styles and aggression. The third recommendation is to apply the mixed method of research, in other words, the qualitative/quantitative or quantitative/qualitative. The current analysis shows that most of the studies used qualitative methods for analyzing the relationship. . The focus of most researchers remained within the quantitative method. Future scholars may consider it as a guideline to analyze the relationship. It is also suggested that future scholars may use parenting styles as a different antecedent of aggression. For example, future scholars may use them as a moderating or mediating variable. This will aid in understanding parenting styles and aggression in a different way. Finally, there is strong need to examine the mediating role of parenting styles in aggressive behavior among children. The review of current studies shows that $61.76 \%$ of the studies did not apply the mediator/moderator analysis in their studies. This will draw more insight into the literature. Also, replication of studies in the health sector can be helpful in generalizing the results.

Compliance with ethical standards, conflict of interest: The authors declare that they have no competing interests. 


\section{References:}

Álvarez-García, D., García, T., Barreiro-Collazo, A., Dobarro, A., \& Antúnez, Á. (2016). Parenting style dimensions as predictors of adolescent antisocial behavior. Frontiers in psychology, 7, 1383.

Azimi, A. L., Vaziri, S., \& Kashani, F. L. (2012). The relationship between Maternal Parenting Style and Child's Aggressive Behavior. Procedia-Social and Behavioral Sciences, 69, 1276-1281.

Bandura, A. (1973). Aggression: A social learning analysis. Prentice-Hall.

Barry, C. T., Frick, P. J., \& Grafeman, S. J. (2008). Child versus parent reports of parenting practices: Implications for the conceptualization of child behavioral and emotional problems. Assessment, 15, 294-303.

Barnes, G. M., \& Farrell, M. P. (1992). Parental support and control as predictors of adolescent drinking, delinquency, and related problem behaviors. Journal of Marriage and the Family, 763-776.

Batool, S. S. (2013). Lack of adequate parenting: A potential risk factor for aggression among adolescents. Pakistan Journal of Psychological Research, 28(2), 217.

Baumrind, D. (1991). Effective parenting during the early adolescent transition. Family transitions, 2(1), 1

Baumrind, D. (1996). The discipline controversy revisited. Family relations, 405-414.

Baumrind, D. (1978). Parental disciplinary patterns and social competence in children. Youth \& Society, 9(3), 239-267.

Baumrind, D. (1971). Current patterns of parental authority. Developmental psychology, 4(1p2), 1.

Baumrind, D. (1966). Effects of authoritative parental control on child behavior. Child development, 887-907.

Bayer, C. L., \& Cegala, D. J. (1992). Trait verbal aggressiveness and argumentativeness: Relations with parenting style. Western Journal of Communication (Includes Communication Reports), 56(3), 301-310. 
Bergman, L. R., \& Andershed, A. K. (2009). Predictors and outcomes of persistent or age-limited registered criminal behavior: A 30-year longitudinal study of a Swedish urban population. Aggressive behavior, 35(2), 164-178.

Beyers, J. M., Bates, J. E., Pettit, G. S., \& Dodge, K. A. (2003). Neighborhood structure, parenting processes, and the development of youths' externalizing behaviors: A multilevel analysis. American Journal of Community Psychology, 31, 35-53.

Brook, J. S., Zheng, L., Whiteman, M., \& Brook, D. W. (2001). Aggression in toddlers: Associations with parenting and marital relations. The journal of genetic psychology, 162(2), 228-241.

Brown, B. B., Mounts, N., Lamborn, S. D., \& Steinberg, L. (1993). Parenting practices and peer group affiliation in adolescence. Child development, 64(2), 467-482.

Carlo, G., Mestre, M. V., Samper, P., Tur, A., \& Armenta, B. E. (2010). Feelings or cognition? Moral cognition and emotions as longitudinal predictors of prosocial and aggressive behaviors. Personality and Individual Differences, 48(8), 872-877.

Carpenter, J. L., \& Mendez, J. (2013). Adaptive and challenged parenting among African American mothers: Parenting profiles relate to head start children's aggression and hyperactivity. Early Education \& Development, 24(2), 233-252.

Casas, J. F., Weigel, S. M., Crick, N. R., Ostrov, J. M., Woods, K. E., Yeh, E. A. J., \& Huddleston-Casas, C. A. (2006). Early parenting and children's relational and physical aggression in the preschool and home contexts. Journal of Applied Developmental Psychology, 27(3), 209-227.

Chan, S. M. (2010). Aggressive behavior in early elementary school children: Relations to authoritarian parenting, children's negative emotionality and coping strategies. Early Child Development and Care, 180(9), 1253-1269.

Chan, S. M. (2011). Social competence of elementary-school children: relationships to maternal authoritativeness, supportive maternal responses and children's coping strategies. Child: care, health, and development, 37(4), 524-532.

Chan, J. Y., Harlow, A. J., Kinsey, R., Gerstein, L. H., \& Fung, A. L. C. (2018). The examination of authoritarian parenting styles, specific forms of peer-victimization, and reactive aggression in Hong Kong Youth. School psychology international, 39(4), 378399. 
Chen, X., Chang, L., He, Y., \& Liu, H. (2005). The peer group as a context: Moderating effects on relations between maternal parenting and social and school adjustment in Chinese children. Child Development, 76(2), 417-434.

Coie, J. D., \& Dodge, K. A. (1998). Aggression and antisocial behavior.

Collins, W. A., \& Laursen, B. (Eds.). (1999). Relationships as developmental contexts: The Minnesota symposia on child psychology (Vol. 30). Psychology Press.

Collins, W. A., \& Steinberg, L. (2006). Adolescent development in interpersonal context (Vol. 4). New York: Cambridge University Press.

Crick, N. R., Werner, N. E., Casas, J. F., O'Brien, K. M., Nelson, D. A., Grotpeter, J. K., \& Markon, K. (1999). Childhood aggression and gender: A new look at an old problem. In Nebraska symposium on motivation (Vol. 45, pp. 75-142). University of Nebraska Press.

Chen, X., Wu, H., Chen, H., Wang, L., \& Cen, G. (2001). Parenting practices and aggressive behavior in Chinese children. Parenting: Science and practice, 1(3), 159-184.

Cleveland, E. S. (2014). Digit ratio, emotional intelligence and parenting styles predict female aggression. Personality and individual differences, 58, 9-14.

Delores, E. S. a., \& Todd, M. M. (2012). Parenting style and psychosocial outcomes in a sample of Jamaican adolescents. International Journal of Adolescence and Youth, 18, 176-190

Dodge, K. A., Coie, J. D., \& Lynam, D. (2006). Aggression and antisocial behavior in youth. Handbook of child psychology.

Dodge, K. A., Pettit, G. S., McClaskey, C. L., Brown, M. M., \& Gottman, J. M. (1986). Social competence in children. Monographs of the society for research in child development, i85 .

Eider, P. S., Aitziber, A., Francisco, B., Ana, I. V., Jaione, C., \& José, R. S. M. (2014). Parenting Styles and Hormone Levels as Predictors of Physical and Indirect Aggression in Boys and Girls. AGGRESSIVE BEHAVIOR, 9999, 1-9.

Ehrenreich, S. E., Beron, K. J., Brinkley, D. Y., \& Underwood, M. K. (2014). Family predictors of continuity and change in social and physical aggression from ages 9 to 18. Aggressive behavior, 40(5), 421-439.

Emily, S. C. (2014). Digit ratio, emotional intelligence, and parenting styles predict female aggression. Personality and Individual Differences, 58 9-14. 
Finzi-Dottan, R., Bilu, R., \& Golubchik, P. (2011). Aggression and conduct disorder in former Soviet Union immigrant adolescents: The role of parenting style and ego identity. Children and Youth Services Review, 33(6), 918-926.

Freud, S. (1937). Analysis terminable and interminable. The International Journal of PsychoAnalysis, 18, 373.

Fung, A. L. C., Gerstein, L. H., Chan, Y., \& Hurley, E. (2013). Children's aggression, parenting styles, and distress for Hong Kong parents. Journal of Family Violence, 28(5), 515-521.

Gao, Y., Zhang, W., \& Fung, A. L. C. (2015). The associations between parenting styles and proactive and reactive aggression in Hong Kong children and adolescents. International journal of psychology, 50(6), 463-471.

Gómez-Ortiz, O., Del Rey, R., Casas, J. A., \& Ortega-Ruiz, R. (2014). Parenting styles and bullying involvement/Estilos parentales e implicación en bullying. Cultura y Educación, 26(1), 132-158.

Greening, L., Stoppelbein, L., \& Luebbe, A. (2010). The moderating effects of parenting styles on African-American and Caucasian children's suicidal behaviors. Journal of youth and adolescence, 39(4), 357-369.

Healey, D. M., Flory, J. D., Miller, C. J., \& Halperin, J. M. (2011). Maternal positive parenting style is associated with better functioning in hyperactive/inattentive preschool children. Infant and Child Development, 20(2), 148-161.

Hesari, N. K. Z., \& Hejazi, E. (2011). The mediating role of self-esteem in the relationship between the authoritative parenting style and aggression. Procedia-social and behavioral sciences, 30, 1724-1730.

Huesmann, L. R., Dubow, E. F., \& Boxer, P. (2009). Continuity of aggression from childhood to early adulthood as a predictor of life outcomes: Implications for the adolescent-limited and life-course-persistent models. Aggressive behavior, 35(2), 136-149.

Jia, S., Wang, L., \& Shi, Y. (2014). Relationship between parenting and proactive versus reactive aggression among Chinese preschool children. Archives of psychiatric nursing, 28(2), 152-157.

Junior, M. L., \& Godinho Filho, M. (2010). Variations of the kanban system: Literature review and classification. International Journal of Production Economics, 125(1), 13-21. 
Kawabata, Y., Alink, L. R., Tseng, W. L., Van Ijzendoorn, M. H., \& Crick, N. R. (2011). Maternal and paternal parenting styles associated with relational aggression in children and adolescents: A conceptual analysis and meta-analytic review. Developmental review, 31(4), 240-278.

Kazdin, A. E., \& Frame, C. (1991). Aggressive behavior and conduct disorder. The Practice of Child Therapy. New York. Pergamon.

Kim, I. J., Ge, X., Brody, G. H., Conger, R. D., Gibbons, F. X., \& Simons, R. L. (2003). Parenting behaviors and the occurrence and co-occurrence of depressive symptoms and conduct problems among African American children. Journal of Family Psychology, 17, 571-583.

Kokkinos, C. M., \& Voulgaridou, I. (2017). Links between relational aggression, parenting and personality among adolescents. European Journal of Developmental Psychology, 14(3), 249-264.

Ladd, G. W., \& Burgess, K. B. (1999). Charting the relationship trajectories of aggressive, withdrawn, and aggressive/withdrawn children during early grade school. Child development, 70(4), 910-929.

Lau, A. S., Takeuchi, D. T., \& Alegrı'a, M. (2006). Parent-to-child aggression among AsianAmerican parents: Culture, context, and vulnerability. Journal of Marriage and the Family, 68, 1261-1275.

Lamborn, Mounts, Steinberg \& Dornbusch, (1991). Patterns of competence and adjustment among adolescents from authoritative, authoritarian, indulgent, and neglectful families. Child development, 62(5), 1049-1065

Lewis, C. C. (1981). The effects of parental firm control: A reinterpretation of findings. Psychological Bulletin, 90(3), 547.

Llorca, A., Richaud, M. C., \& Malonda, E. (2017). Parenting styles, prosocial, and aggressive behavior: The role of emotions in offender and non-offender adolescents. Frontiers in psychology, 8, 1246.

Liu, M., \& Guo, F. (2010). Parenting practices and their relevance to child behaviors in Canada and China. Scandinavian Journal of Psychology, 51(2), 109-114. 
Lorber, M. F., Egeland, B., \& problems. (2011). Parenting and infant difficulty: Testing a mutual exacerbation hypothesis to predict early onset conduct. Child Development, 82, 20062020 .

Marion, K. U., Kurt, J. B., \& Lisa, H. R. (2009). Continuity and Change in Social and Physical Aggression from Middle Childhood through Early Adolescence. AGGRESSIVE BEHAVIOR, 35, 357-375.

Martínez, I., Murgui, S., García, O. F., \& García, F. (2019). Parenting in the digital era: Protective and risk parenting styles for traditional bullying and cyberbullying victimization. Computers in Human Behavior, 90, 84-92.

McNamara, K. A., Selig, J. P., \& Hawley, P. H. (2010). A typological approach to the study of parenting: Associations between maternal parenting patterns and child behavior and social reception. Early Child Development and Care, 180, 1185-1202.

McKee, L., Colletti, C., Rakow, A., Jones, D. J., \& Forehand, R. (2008). Parenting and child externalizing behaviors: Are the associations specific or diffuse? Aggression and Violent Behavior, 13, 201-215.

Milevsky, A., Schlechter, M., Netter, S., \& Keehn, D. (2007). Maternal and paternal parenting styles in adolescents: Associations with self-esteem, depression and lifesatisfaction. Journal of child and family studies, 16(1), 39-47.

Mowder, B. A. (2005). Parent development theory: Understanding parents, parenting perceptions, and parenting behaviors. Journal of Early Childhood and Infant Psychology, $1,46-64$.

Murray-Close, D., \& Ostrov, J. M. (2009). A longitudinal study of forms and functions of aggressive behavior in early childhood. Child Development, 80(3), 828-842.

Muñoz, J. M., Braza, P., Carreras, R., Braza, F., Azurmendi, A., Pascual-Sagastizábal, E., ... \& Sánchez-Martín, J. R. (2017). Daycare center attendance buffers the effects of maternal authoritarian parenting style on physical aggression in children. Frontiers in psychology, 8, 391.

Nelson, D. A., Hart, C. H., Yang, C., Olson, J. A., \& Jin, S. (2006). Aversive parenting in China: Association with child physical and relational aggression. Child Development, 77, 554572. 
Pascual-Sagastizabal, E., Azurmendi, A., Braza, F., Vergara, A. I., Cardas, J., \& Sánchez-Martín, J. R. (2014). Parenting styles and hormone levels as predictors of physical and indirect aggression in boys and girls. Aggressive behavior, 40(5), 465-473.

Patterson, G. R., Chamberlain, P., \& Reid, J. B. (1982). A comparative evaluation of a parenttraining program. Behavior therapy, 13(5), 638-650.

Raine, A. (2002). Biosocial studies of antisocial and violent behavior in children and adults: A review. Journal of abnormal child psychology, 30(4), 311-326.

Reed, T. J., Goldstein, S. E., Morris, A. S., \& Keyes, A. W. (2008). Relational aggression in mothers and children: Links with psychological control and child adjustment. Sex Roles, 59(1-2), 39-48.

Robins, L. N. (1966). Deviant children grown up, a sociological and psychiatric study of sociopathic personality.

Rodriguez, C. M. (2010). Parent-child aggression: Association with child abuse potential and parenting styles. Violence and Victims, 25(6), 728-741.

Romano, E., Tremblay, R., Boulerice, B., \& Swisher, R. R. (2005). Multilevel correlates of childhood physical aggression and prosocial behavior. Journal of Abnormal Child Psychology, 33, 565-578.

Russell, A., Hart, C., Robinson, C., \& Olsen, S. (2003). Children's sociable and aggressive behaviour with peers: A comparison of the US and Australia, and contributions of temperament and parenting styles. International journal of behavioral development, 27(1), 74-86.

Rutter, M., \& Quinton, D. (1984). Parental psychiatric disorder: Effects on children. Psychological medicine, 14(4), 853-880.

Sánchez-Martín, J. R., Azurmendi Imaz, A., Fano Ardanaz, E., Braza Lloret, F., Muñoz Sánchez, J. M., \& Carreras de Alba, M. R. (2009). Niveles de andrógenos, estilos parentales y conducta agresiva en niños y niñas de 5-6 años de edad. Psicothema, 21(1).

Schwerdtfeger, K. L., Larzelere, R. E., Werner, D., Peters, C., \& Oliver, M. (2013). Intergenerational transmission of trauma: The mediating role of parenting styles on toddlers' DSM-related symptoms. Journal of Aggression, Maltreatment \& Trauma, 22(2), 211-229. 
Shoumei, J. a., Ling, W. b., \& Yingjuan, S. (2014). Relationship Between Parenting and Proactive Versus Reactive Aggression Among Chinese Preschool Children. Archives of Psychiatric Nursing, 28, 152-157.

Smith, D. E., \& Moore, T. M. (2013). Parenting style and psychosocial outcomes in a sample of Jamaican adolescents. International Journal of Adolescence and Youth, 18(3), 176-190.

Smith, S., Mullis, F., Kern, R. M., \& Brack, G. (1999). An Adlerian model for the etiology of aggression in adjudicated adolescents. The Family Journal, 7(2), 135-147.

Steinberg, L., Lamborn, S. D., Darling, N., Mounts, N. S., \& Dornbusch, S. M. (1994). Over-time changes in adjustment and competence among adolescents from authoritative, authoritarian, indulgent, and neglectful families. Child development, 65(3), 754-770.

Steinberg, L. (1990). Authoritative parenting and adolescent adjustment across varied ecological niches.

Steinberg, L., Elmen, J. D., \& Mounts, N. S. (1989). Authoritative parenting, psychosocial maturity, and academic success among adolescents. Child development, 1424-1436.

Slicker, E. K. (1998). Relationship of parenting style to behavioral adjustment in graduating high school seniors. Journal of Youth and Adolescence, 27(3), 345-372.

Servatyari, K., Yousefi, F., Kashefi, H., Bahmani, M. P., Parvareh, M., \& Servatyari, S. (2018). The relationship between parenting styles with the aggression of their children in sanandaj primary students. International Journal of Biomedicine and Public Health, 1(3), $142-148$.

Tiina, O.-A., Jari-Erik, N., \& Kaisa, A. (1998). Mothers' and fathers' well-being, parenting styles, and their children's cognitive and behavioral strategies at primary school. European Journal ojPsychology of Education, 8, 543-556.

Tremblay, R. E., Nagin, D. S., Séguin, J. R., Zoccolillo, M., Zelazo, P. D., Boivin, M., ... \& Japel, C. (2004). Physical aggression during early childhood: Trajectories and predictors. Pediatrics, 114(1), e43-e50.

Trenas, A. F. R., Osuna, M. J. P., Olivares, R. R., \& Cabrera, J. H. (2013). Relationship between parenting style and aggression in a Spanish children sample. Procedia-Social and Behavioral Sciences, 82, 529-536.

Kawabata, Y., Alink, L. R., Tseng, W. L., Van Ijzendoorn, M. H., \& Crick, N. R. (2011). Maternal and paternal parenting styles associated with relational aggression in children 
and adolescents: A conceptual analysis and meta-analytic review. Developmental Review, 31(4), 240-278.

Underwood, M. K., Beron, K. J., \& Rosen, L. H. (2009). Continuity and change in social and physical aggression from middle childhood through early adolescence. Aggressive Behavior: Official Journal of the International Society for Research on Aggression, 35(5), 357-375.

Underwood, M. K., Beron, K. J., Gentsch, J. K., Galperin, M. B., \& Risser, S. D. (2008). Family correlates of children's social and physical aggression with peers: Negative interparental conflict strategies and parenting styles. International Journal of Behavioral Development, 32(6), 549-562. 